\title{
Chronic persistent cough and gastro-oesophageal reflux
}

\author{
A J Ing, M C Ngu, A B X Breslin
}

\begin{abstract}
Chronic cough persisting for two months or more that remains unexplained after extensive investigations is a common clinical problem. The purpose of this study was to determine whether such cough is associated with otherwise asymptomatic gastro-oesophageal reflux. Thirteen patients with chronic persistent cough that was unexplained after a standard diagnostic assessment were identified. All were non-smokers. The mean (SE) duration of cough was $17 \cdot 8(8 \cdot 0)$ months. Ten had never had reflux symptoms and three had had mild symptoms only after the onset of the cough. All the patients completed standardised cough diary cards for eight weeks and underwent 24 hour ambulatory oesophageal pH monitoring. A reflux episode was defined as a fall in oesophageal $\mathrm{pH}$ to below 4.0. Nine control subjects were matched for age, lung function, and body mass index. The patients experienced significantly more episodes of reflux per 24 hours than the controls (115.8 (SE $31.7)$ versus $4.7(1.4)$ and longer reflux episodes $(15.5(5.8)$ versus $1.7(0.5) \mathrm{min}$ utes), and the oesophageal $\mathrm{pH}$ was below 4.0 considerably longer $(84.5(20.2)$ versus 3.8 (1.3) minutes). Cough occurred simultaneously with $13 \%(2 \cdot 2 \%)$ of reflux episodes and within five minutes in another $35 \%(5 \cdot 8 \%)$ of episodes, whereas gastro-oesophageal reflux occurred simultaneously with $78 \%(5 \cdot 5 \%)$ of cough episodes and within five minutes in another $12 \%(2 \cdot 3 \%)$ of episodes. It is concluded that chronic persistent cough that remains unexplained after a standard diagnostic assessment is associated with otherwise asymptomatic gastro-oesophageal reflux. It is suggested that a self perpetuating mechanism may exist whereby acid reflux causes cough via a local neuronal oesophageal-tracheobronchial reflex, and the cough in turn amplifies reflux via increased transdiaphragmatic pressure or by inducing transient lower oesophageal sphincter relaxation. Further study of this mechanism and the role of specific antireflux treatment in chronic persistent cough is warranted.
\end{abstract}

Chronic persistent cough is a common clinical problem. Previous studies have suggested that the cause can nearly always be determined, on the basis of an anatomical diagnostic protocol, and the cough subsequently treated. ${ }^{12}$ Others, however, using this same protocol have found that over $10 \%$ of chronic cough remains unexplained. $^{34}$

Gastro-oesophageal reflux has been found to cause $4-21 \%$ of chronic cough, ${ }^{1-5}$ but in these studies most patients had symptoms or other clinical indicators suggesting reflux. Irwin and coworkers, in an uncontrolled study of nine patients, showed that cough may be the sole presentation of gastro-oesophageal reflux. ${ }^{6}$ The aim of the present controlled study was to determine whether chronic persistent cough that remains unexplained after an extensive diagnostic evaluation is associated with otherwise asymptomatic gastro-oesophageal reflux.

\section{Methods}

Subjects identified as having chronic cough of unknown aetiology underwent 24 hour ambulatory oesophageal $\mathrm{pH}$ monitoring. The results were compared with those from a matched control group. Informed consent was obtained from all subjects, and the study was approved by the local ethics committee.

\section{STUDY DESIGN}

To be selected to undergo 24 hour ambulatory oesophageal $\mathrm{pH}$ monitoring subjects had to meet specific inclusion and exclusion criteria, after undergoing a standard diagnostic assessment.

Inclusion criteria were the presence of chronic cough, defined as troublesome daily cough for at least two months, in subjects aged 18-75 years.

The standard diagnostic evaluation consisted of a full history and physical examination, chest radiography, and lung function testing, including spirometry and measurement of lung volumes and transfer factor for carbon monoxide (TLCO). Spirometry was performed with a water sealed spirometer (Jaeger) according to American Thoracic Society guidelines. ${ }^{7}$ Lung volumes were determined with a modular lung analyser using helium dilution (Collins). Transfer factor for carbon monoxide was determined via the single breath method, with the same analyser and according to American Thoracic Society guidelines. ${ }^{8}$ All subjects performed home peak expiratory flow monitoring twice daily for at least three weeks and all had histamine inhalation tests as described by Yan et al $^{9}$; ear, nose, and throat examination; para-
Concord Hospital, Australia

Reprint requests to: Dr Ing

Accepted 17 April 1991 
Table 1 Characteristics of patients and control subjects (mean (SE) values) *

\begin{tabular}{llr}
\hline & Patients & \multicolumn{1}{c}{ Controls } \\
\hline Age (y) & $48 \cdot 7(5 \cdot 2)$ & $47 \cdot 7(5 \cdot 6)$ \\
Body mass index & $24 \cdot 1(1 \cdot 1)$ & $22 \cdot 9(0 \cdot 6)$ \\
FEV $_{1}(\%$ pred) & $97 \cdot 8(2 \cdot 7)$ & $101 \cdot 1(3 \cdot 4)$ \\
Forced vital capacity (\% pred) & $92 \cdot 4(3 \cdot 6)$ & $96 \cdot 8(4 \cdot 0)$
\end{tabular}

^All differences non-significant as calculated by Student's $t$ test (two tailed).

nasal sinus radiography, skin prick tests with 23 common allergens, and quantitative immunoglobulin estimations.

Subjects with asthma, sinusitis, postnasal drip, chronic bronchitis, and allergic rhinitis were excluded from the study. The diagnosis of asthma was made on historical grounds (cough, wheeze, and dyspnoea with specific precipitating factors) in addition to a $\mathbf{P D}_{20}$ histamine value (the provocative dose causing a $20 \%$ fall in $\mathrm{FEV}_{1}$ ) below $4 \mu \mathrm{mol} / 1$ or more than $15 \%$ variability in home peak expiratory flow rate monitoring. Sinusitis and postnasal drip were diagnosed from the history and by the finding of oedematous, hyperaemic nasal mucosa or abnormal paranasal sinus radiographs. Chronic bronchitis was diagnosed in patients with chronic cough and sputum for at least two months a year for two consecutive years. Allergic rhinitis was diagnosed from appropriate symptoms when associated with positive skin prick test responses (weal at least $2 \times 2 \mathrm{~mm}$ greater than control with at least one antigen).

Subjects were also excluded from our study if they had symptoms of gastro-oesophageal reflux before the onset of cough or if they had an acute respiratory infection (or had had one within two months of the study), pulmonary malignancy, interstitial lung disease, or appreciable cardiac or renal disease.

Smokers were excluded because of the known effects of bronchial irritation and relaxation of the lower oesophageal spincter tone by tobacco smoke, ${ }^{10}$ as were patients taking theophylline, which also reduces lower oesophageal spincter tone, ${ }^{11}$ and those taking angiotensin converting enzyme inhibitors.

Subjects fulfilling all inclusion and exclusion criteria completed standardised cough diary cards for eight weeks, recording cough scores twice daily. Two weeks from the start of this period 24 hour ambulatory oesophageal $\mathrm{pH}$ monitoring was performed. The $\mathrm{pH}$ recorder and oesophageal and skin electrodes were calibrated before the procedure, calibrating $\mathrm{pH}$ buffer solutions with $\mathrm{pH}$ values of 1.00 and 7.00 being used. A $3 \mathrm{~mm}$ diameter oesophageal $\mathrm{pH}$ catheter with a polycrystalline antimony $\mathrm{pH}$ electrode at its tip was passed transnasally into the oesophagus and positioned $10 \mathrm{~cm}$ above the gastro-oesophageal junction (determined by the change in $\mathrm{pH}$ between the stomach and oesophagus). The catheter was taped to the nose and, with a skin electrode taped to the anterior abdominal wall, was attached to a 24 hour oesophageal $\mathrm{pH}$ recorder (Synetics Digitraper MkII). The recorder had an event (cough) marker, which subjects were instructed to activate to denote the timing of each cough on the $\mathrm{pH}$ tracing.

The subjects also kept a comprehensive diary, recording the timing of cough, meals, body position (supine or upright), reflux symptoms, and other intercurrent symptoms. During the 24 hours when oesophageal $\mathrm{pH}$ was

Table 2 Twenty four hour ambulatory oesophageal pH monitoring data for patients and controls

\begin{tabular}{|c|c|c|c|c|c|c|}
\hline Patient No & $\begin{array}{l}\text { Total No of } \\
\text { refluxes }\end{array}$ & $\begin{array}{l}\text { Total refluxes } \\
>5 \mathrm{~min}\end{array}$ & $\begin{array}{l}\text { Longest reflux } \\
\text { (min) }\end{array}$ & $\begin{array}{l}\text { Time (min) spent } \\
\text { at } p H<4\end{array}$ & $\begin{array}{l}\% 24 \text { hat } \\
p H<4\end{array}$ & $\begin{array}{l}\text { No of cough } \\
\text { episodes }\end{array}$ \\
\hline $\begin{array}{r}1 \\
2 \\
3 \\
4 \\
5 \\
6 \\
7 \\
8 \\
9 \\
10 \\
11 \\
12 \\
13\end{array}$ & $\begin{array}{r}82 \\
25 \\
338 \\
58 \\
71 \\
270 \\
44 \\
73 \\
320 \\
18 \\
71 \\
22 \\
114\end{array}$ & $\begin{array}{r}7 \\
2 \\
6 \\
5 \\
4 \\
8 \\
4 \\
3 \\
14 \\
0 \\
5 \\
0 \\
7\end{array}$ & $\begin{array}{r}17 \\
4 \\
71 \\
1 \\
7 \\
5 \\
14 \\
26 \\
2 \\
3 \\
46 \\
1 \\
5\end{array}$ & $\begin{array}{r}115 \\
8 \\
200 \\
16 \\
83 \\
76 \\
69 \\
239 \\
47 \\
20 \\
138 \\
7 \\
81\end{array}$ & $\begin{array}{r}8.3 \\
0.6 \\
13.9 \\
1.2 \\
5.8 \\
5.5 \\
4.8 \\
16.8 \\
3.3 \\
1.4 \\
9.6 \\
0.5 \\
6.2\end{array}$ & $\begin{array}{r}43 \\
9 \\
52 \\
8 \\
32 \\
21 \\
27 \\
64 \\
25 \\
12 \\
45 \\
7 \\
38\end{array}$ \\
\hline $\begin{array}{l}\text { Mean } \\
\text { Median } \\
\text { SE }\end{array}$ & $\begin{array}{r}115 \cdot 8 \\
71 \cdot 0 \\
31 \cdot 7\end{array}$ & $\begin{array}{l}5 \cdot 0 \\
5 \cdot 0 \\
1.0\end{array}$ & $\begin{array}{r}15 \cdot 5 \\
5 \cdot 0 \\
5 \cdot 8\end{array}$ & $\begin{array}{l}84 \cdot 5 \\
76 \cdot 0 \\
20 \cdot 2\end{array}$ & $\begin{array}{l}6 \cdot 0 \\
5 \cdot 5 \\
1 \cdot 4\end{array}$ & $\begin{array}{r}29 \cdot 5 \\
27 \cdot 0 \\
5 \cdot 1\end{array}$ \\
\hline $\begin{array}{l}\text { Control no } \\
1 \\
2 \\
3 \\
4 \\
5 \\
6 \\
7 \\
8 \\
9\end{array}$ & $\begin{array}{r}2 \\
1 \\
7 \\
0 \\
0 \\
12 \\
5 \\
9 \\
6\end{array}$ & $\begin{array}{l}0 \\
0 \\
0 \\
0 \\
0 \\
0 \\
0 \\
0 \\
0\end{array}$ & $\begin{array}{l}2 \\
1 \\
3 \\
0 \\
0 \\
3 \\
4 \\
1 \\
1\end{array}$ & $\begin{array}{r}4 \\
1 \\
2 \\
0 \\
0 \\
12 \\
8 \\
4 \\
2\end{array}$ & $\begin{array}{l}0.3 \\
0.1 \\
0.1 \\
0 \\
0 \\
0.6 \\
0.6 \\
0.3 \\
0.1\end{array}$ & $\begin{array}{l}0 \\
0 \\
0 \\
0 \\
0 \\
0 \\
0 \\
0 \\
0\end{array}$ \\
\hline $\begin{array}{l}\text { Mean } \\
\text { Median } \\
\text { SE }\end{array}$ & $\begin{array}{l}4 \cdot 7 \\
5 \\
1 \cdot 4\end{array}$ & $\begin{array}{l}0 \\
0 \\
0\end{array}$ & $\begin{array}{l}1 \cdot 7 \\
1.0 \\
0.5\end{array}$ & $\begin{array}{l}3 \cdot 8 \\
1 \cdot 3 \\
1 \cdot 3\end{array}$ & $\begin{array}{l}0 \cdot 2 \\
0 \cdot 1 \\
0 \cdot 1\end{array}$ & $\begin{array}{l}0 \\
0 \\
0\end{array}$ \\
\hline$p^{\star}$ & $<0.0001$ & $<0.001$ & $<0.007$ & $<0.0001$ & $<0.0001^{\circ}$ & $<0.0001$ \\
\hline
\end{tabular}

^Wilcoxon rank sum test (two tailed). 
being recorded subjects underwent their usual daily activities, except that they were asked to avoid foods and liquids containing caffeine or with an acidic $\mathrm{pH}$, such as citrus fruits and fruit juices, and dairy products including milk. The recording period was greater than 24 hours by design, but only the data collected in the first 24 hours were analysed, to obviate the need to extrapolate data.

After the monitoring period the $\mathrm{pH}$ recorder was interfaced with an IBM XT computer and the data were analysed with commercially available software (Esophogram, Gastrosoft). A reflux episode was defined as a fall in oesophageal $\mathrm{pH}$ below 4.0 and the end of a reflux event as a return of oesophageal $\mathrm{pH}$ to more than 5.0. Diary events were entered manually on to the $\mathrm{pH}$ tracing before data analysis, and the timing of these events and their relation to oesophageal $\mathrm{pH}$ analysed. The following variables were determined: total duration of each recorded event, total number of reflux episodes, number of reflux episodes longer than five minutes, longest reflux episode, total time and percentage of time oesophageal $\mathrm{pH}$ was less than $4 \cdot 0$, total number of cough events, number of cough events occurring simultaneously with reflux episodes and number occurring within five minutes of reflux episodes, and number of reflux episodes occurring simultaneously with cough episodes and number occurring within five minutes of cough.

Normal control subjects matched for age, body mass index, and lung function also underwent 24 hour ambulatory oesophageal $\mathrm{pH}$ monitoring. Control subjects fulfilled all inclusion and exclusion criteria except for chronic cough. No normal subjects were studied and rejected.

For analysis of the relation between cough and reflux episodes the following criteria were applied empirically:

(1) Events were said to be simultaneous when they were superimposed on one another on the 24 hour oesophageal $\mathrm{pH}$ trace.

(2) Events were said to bear a temporal relationship when they occurred within five minutes of each other.

(3) Events were said to be unrelated when they occurred more than five minutes apart.

\section{STATISTICAL ANALYSIS}

Normally distributed variables were analysed with Student's $t$ test (two tailed). Variables not distributed normally were analysed by the Wilcoxon rank sum test (two tailed). The defined level of significance was $p<0.01$ in all analyses.

\section{Results}

SUBJECTS' CHARACTERISTICS

Thirteen patients (seven male, six female) were identified over 9 months (May 1989 to January 1990) as having a chronic, persistent cough of unkown aetiology by the above criteria. Their mean (SE) age was $48 \cdot 7(5 \cdot 2)$ years and all had normal body mass index and lung function (table 1). The mean duration of cough on
Twenty four hour ambulatory oesophageal pH monitoring: tracings from a patient and $a$ control subject. $x$ axistime (over 24 hours); $y$ axis-oesophageal $\mathrm{p} H$, $M-$ meals; $P$ -

postprandial; $S$-supine position; $\mathrm{K}$-cough; $\mathrm{H}-$ cough.

\section{CONIROL}
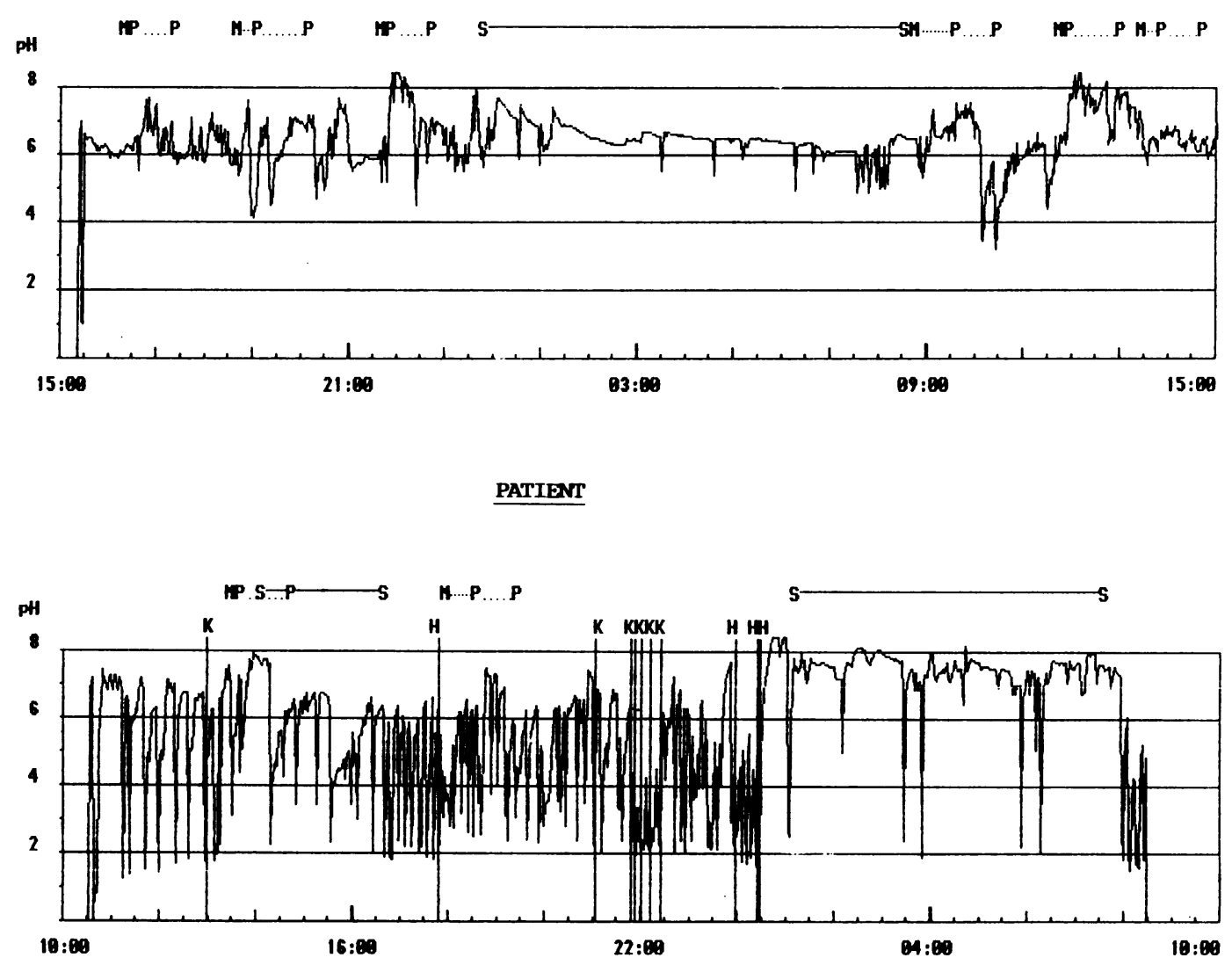
presentation was $17.4(8.0)$ months. Nine subjects had never smoked and four had smoked previously, but all had ceased more than 10 years before the study. Ten patients had never had symptoms of gastro-oesophageal reflux, and three developed mild reflux symptoms only after the onset of cough. For all patients the provocative dose of histamine causing a $20 \%$ fall in $\mathrm{FEV}_{1}\left(\mathrm{PD}_{20}\right)$ was above $8 \mu \mathrm{mol}$.

Nine matched controls (four male, and five female) were identified over the same period. There were no significant differences in age, body mass index, or lung function between the control subjects and the patients (table 1). Six of the control subjects had never smoked, three had smoked previously but had stopped more than 10 years before the study. Seven had never had symptoms of gastro-oesophageal reflux. Two have had occasional mild postprandial reflux symptoms, which had never been troublesome or reported to their family doctor. The histamine PD20 was above $8 \mu \mathrm{mol}$ in all subjects.

\section{HOUR AMBULATORY OESOPHAGEAL PH MONITORING}

All patients and control subjects completed 24 hour ambulatory oesophageal $\mathrm{pH}$ monitoring. There were no significant adverse reactions to the procedure reported.

Patients had significantly more reflux events/ 24 hours $(115 \cdot 8(31 \cdot 7)$ versus $4 \cdot 7(1 \cdot 4)$ than the control subjects, more reflux events of more than five minutes duration $(5 \cdot 0(1 \cdot 0) v 0 \cdot 0(0 \cdot 0)$, longer reflux episodes $(15.5(5.8) v 1.7(0.5)$ minutes), and oesophageal $\mathrm{pH}$ below 4.0 for a longer time $(84.5(20.2)$ v $3.8(1.3)$ minutes) (table 2 ). The figure shows a typical oesophageal $\mathrm{pH}$ recording for a patient who had had pronounced falls in oesophageal $\mathrm{pH}$ related to cough and for a control subject.

There were no recorded cough events in the control group on the $\mathrm{pH}$ trace, as determined by the event (cough) marker, or in diary cards during the 24 hour period, nor did any control subject report symptoms of gastro-oesophageal reflux. The patients had a mean of $29 \cdot 5(5 \cdot 1)$ cough events during the 24 hour monitoring period. Eleven patients reported no reflux symptoms during the 24 hour monitoring period, whereas two reported a total of eight episodes of heartburn. These generally occurred after a meal. All eight episodes were associated with an oesophageal $\mathrm{pH}$ below 4.0.

According to the criteria described, we found that cough occurred simultaneously, with $13 \%$ $(2 \cdot 2 \%)$ of reflux episodes, and within five minutes of an episode in another $35 \%(5.8 \%)$ of episodes, while reflux occurred simultaneously with $78 \%(5.5 \%)$ of cough episodes and within five minutes of an episode in another $12 \%$ $(2 \cdot 3 \%)$. Thus cough was temporally related to more than $48 \%$ of reflux episodes, and reflux was temporally related to more than $90 \%$ of cough episodes.

Gastro-oesophageal reflux occurred predominantly when subjects were in the upright position, so fewer episodes occurred during sleep. Patients spent a mean $62 \%(3 \cdot 1 \%)$ of the
24 hours in the upright position (and 8\% $(2.3 \%)$ in the supine position), whereas $80 \%$ $(4.2 \%)$ of reflux episodes occurred in the upright position (and $21 \%(3.3 \%)$ in the supine position).

\section{Discussion}

Irwin et al found that chronic persistent cough may be the sole presenting manifestation of gastro-oesophageal reflux. ${ }^{6}$ In their report of nine patients with chronic cough eventually attributed to gastro-oesophageal reflux only three had symptoms of reflux initially. His group, however, was heterogenous, four of his nine patients having asthma, which may cause chronic cough, ${ }^{13}$ and may also be associated with reflux. ${ }^{12-14}$ Moreover, Irwin used control data from 24 hour ambulatory oesophageal $\mathrm{pH}$ studies on subjects not matched for his patients. ${ }^{1516}$

In this study we aimed to determine in a prospective manner whether chronic cough is associated with gastro-oesophageal reflux, using a homogenous group of subjects with no other pre-existing conditions and matched control subjects. The results suggest that chronic cough that remains unexplained after a standard diagnostic assessment is associated with otherwise asymptomatic gastro-oesophageal reflux. Only three of our 13 patients have ever had symptoms of reflux, and then only after the onset of cough. The fact that reflux in this group is largely asymptomatic is reflected by the multiple episodes of reflux during the 24 hour monitoring period that were not associated with any symptoms other than cough. Over $90 \%$ of cough episodes were temporally related to reflux, implying that gastrooesophageal reflux may be an important aetiological factor in the development of chronic persistent cough.

The observation that reflux occurred predominantly in the upright position implies that most of our patients have preservation of the normal reflex that suppresses transient lower oesophageal sphincter relaxation in the supine posture. ${ }^{17} \mathrm{~A}$ significant number of reflux episodes still occurred in the supine position (in five patients), however, indicating failure of suppression of transient lower oesophageal sphincter relaxation in these subjects.

The mechanism by which reflux may cause cough in our patients remains unknown. Gross aspiration of gastric contents into the tracheobronchial tree seems unlikely given that all the patients had normal chest radiographs and normal findings from laryngeal examination, and that most were symptomless. When Irwin ${ }^{6}$ and coworkers studied similar patients with proximal oesophageal $\mathrm{pH}$ probes placed at least $2 \mathrm{~cm}$ above the thoracic inlet they found no correlation between cough and any measure of reflux in the proximal oesophagus. Microaspiration remains possible, however.

It seems more likely that gastro-oesopahgeal reflux causes cough via a local oesophagealtracheobronchial reflex, possibly vagally mediated and acid stimulated. Such a reflex has been suggested to occur in some patients with 
asthma, in whom acid in the oesophageal lumen may be responsible for precipitating bronchoconstriction. ${ }^{12-14}{ }^{18}$ Animal experiments support the existence of this reflex. ${ }^{19} \mathrm{We}$ also postulate that a positive feedback cycle may exist in our patients whereby reflux initiates cough by a neural mechanism, and the cough in turn amplifies reflux via transient increases in transdiaphragmatic pressure or by causing transient lower oesophageal sphincter relaxation. This is supported in part by a pilot study in 11 of our 13 patients, in which the histamine $\left(\mathrm{H}_{2}\right)$ antagonist ranitidine, given for two weeks, produced significant reduction in cough as measured by cough diary scores.

Thus we have shown in a controlled study that there is a group of patients with chronic cough that remains unexplained after a standard diagnostic assessment. The group was remarkably homogenous, reflux being associated with cough in all our patients as determined by 24 hour ambulatory oesophageal $\mathrm{pH}$ monitoring. Chronic persistent cough of unknown aetiology remains a common problem that is often difficult to treat. This study shows that otherwise asymptomatic gastro-oesophageal reflux may be an important aetiological factor, and further study into the possible mechanisms may allow for effective treatment of such cough in the future.

1 Irwin RS, Corrao WM, Pratter MR. Chronic persistent cough in the adult: the spectrum and frequency of causes and successful outcome of specific therapy. Am Rev Respir and successful outco

2 Irwin RS, Curley FJ, French CL. Chronic cough: the spectrum and frequency of causes, key components of the diagnostic evaluation, and outcome of specific therapy. $\mathrm{Am}$ Rev Respir Dis 1990;141:640-7.
3 Poe RH, Harder RV, Israel RH, Kallay MC. Chronic persistent cough: experience in diagnosis and outcome using an anatomic diagnostic protocol. Chest 1989;95 723-8.

4 Holinger LD. Chronic cough in infants and children. Laryngoscope 1986;96:316-22.

5 Poe RH, Israel RH, Utell MJ, Hall WJ. Chronic cough: bronchoscopy or pulmonary function testing. Am Rev Respir Dis 1982;126:160-2.

6 Irwin RS, Zawacki JK, Curley FJ, French CL, Hoffman PJ. Chronic cough as the sole presenting manifestation of gastro-oesophageal reflux. Am Rev Respir Dis 1989;140: gastro-oesopt

7 American Thoracic Society. Standardisation of spirometry -1987 update. Am Rev Respir Dis 1987;136:1285-98.

8 American Thoracic Society. Single breath carbon monoxide diffusing capacity (transfer factor). Recommendations for a standard technique. Am Rev Respir Dis 1987;136: $1299-307$.

9 Yan K, Salome C, Woolcock AJ. Rapid method for measurement of bronchial responsiveness. Thorax 1983; 38:760-5.

10 Dennish GW, Castell DO. Inhibitory effect of smoking on the lower oesophageal sphincter. $N$ Engl J Med 1971; 284:1136-7.

11 Stein MR, Towner TG, Weber RW, et al. The effect of theophylline on the lower oesophageal sphincter pressure. Ann Allergy 1980;45:238-41.

12 Goodall RJ, Earis JE, Cooper DN, Bernstein A, Temple JG. Relationship between asthma and gastro-oesophageal reflux. Thorax 181;36:116-21.

13 Boyle JT, Tuchman DN, Altschuler SM, Nixon TE, Pack AI, Cohen S. Mechanisms for the association of gastrooesophageal reflux and bronchospasm. Am Rev Respir Dis 1985;131(suppl):S16-20.

14 Castell DO. Asthma and gastro-oesophageal reflux. Chest 1989;96:2-3.

15 Ward BW, Wu WC, Richter JE, Lui KW, Castell DO Ambulatory 24-hour oesophageal pH monitoring: technology searching for a clinical application. J Clin Gastroenterol 1986;8(suppl I):59-67.

$16 \mathrm{Wu}$ WC. Gastro-oesophageal reflux and $\mathrm{pH}$ testing. In: Castell DO, Richter JE, Dalton CB, eds. Oesophageal motility testing. New York: Elsevier, 1987:198-208.

17 Mansfield LE, Stein MR. Gastro-oesophageal reflux: a possible reflex mechanism. Ann Allergy 1978;41:224-6.

18 Mansfield LE, Hameister $\mathrm{HH}$, Spaulding HS, Smith NJ, Glab $N$. The role of the vagus nerve in airway narrowing caused by intraoesophageal hydrochloric acid provocation and oesophageal distention. Ann Allergy 1981;47:431-4.

19 Dent J. Recent views on the pathogenesis of gastrooesophageal reflux disease. Vol 1 (No 4). In: Ballière's Clinical gastroenterology. 1987;4:727-45. 